\title{
The writing strategy in French language learning among Malaysian students: A qualitative approach
}

\begin{abstract}
This exploratory study aims to determine and categorize the type of strategies used by Malaysian students in their learning French as a foreign language with regards to writing skills by applying Dörnyei's (1995) communication strategies taxonomy. The study utilized both a qualitative and quantitative method of data analysis. A total of 30 subjects participated in this study. The task consisted of the administration of the writing task by the subjects after their 100 hours of learning French. The main instruments used in the study were a writing task prompt and an observation checklist. Instruments were adapted mainly from Dornyei \& Scott (1997).
\end{abstract}

Keyword: Qualitative 